\title{
Lengua de Signos Española y ámbitos específicos. Una propuesta multidiscipli- nar e inclusiva para la búsqueda, análisis y creación de Signos
}

\author{
Aránzazu Valdés-González, Javier Martín-Antón
}

Universidad de Oviedo (España)

\section{RESUMEN}

La presente investigación busca contribuir a que la Lengua de Signos Española (en adelante, LSE) se adecue a las necesidades lingüísticas de las personas Sordas usuarias de LSE como primera lengua y semilingües en lengua oral, favoreciendo la labor del intérprete de LSE en el ámbito educativo.El objetivo de nuestro estudio fue desarrollar un proceso sistemático de búsqueda bibliográfica y análisis de vocablos de diversos ámbitos especializados para, en el caso de no encontrar un Signo adecuado, proceder a la creación y propuesta de un neologismo. Los resultados de la investigación se difundieron a través de audiovisuales de diseño innovador. Se concluye que, los materiales lexicográficos existentes tienen áreas de mejora, especialmente, por la necesidad de actualización y por su aplicabilidad a determinados contextos. En este sentido, el estudio pone en valor que la LSE dispone de mecanismos y recursos de creación léxica que pueden suplir las carencias detectadas lo que pone de relieve que la LSE es una lengua rica y viva con un potencial que debe ser aprovechado. Se concluye, en consecuencia, que mediante el sistema diseñado y experimentado cualquier término perteneciente a una lengua oral puede transmitirse mediante una lengua de modalidad viso-gestual como la LSE.

Palabras clave: Lengua de Signos Española, materiales lexicográficos, educación inclusiva, neologismos, interpretación.

\section{Spanish Sign Language and specific areas. A multidisciplinary and inclusive proposal for the search, analysis and creation of Signs}

\section{ABSTRACT}

This research seeks to contribute to the Spanish Sign Language (hereinafter LSE) adapting to the Linguistics needs of LSE Deaf People as first language and semilingual in the oral language, further favoring the work of the LSE Interpreter. The objective of our study was to develop a systematic process of bibliographic search and analysis of words from various specialized fields so, in the case of not finding an appropriate sign, proceed to the creation and proposal of a neologism. The results of the research were disseminated through audiovisuals of innovative design. It is concluded that existing lexicographic materials have areas of improvement, especially because of the need for updating and their applicability to certain contexts. In this sense, the study values that the LSE has lexical creation mechanisms and resources that can fill the identified gaps which highlights that the LSE is a rich and living language with a potential that must be exploited. It is therefore concluded that any term belonging to an oral language can be transmitted by means of a visual-gestual language such as the LSE through the system designed and experienced.

Keywords: Spanish Sign Language, lexicographic materials, lexicon, inclusion, deafness. 


\section{Introducción}

Las lenguas signadas -y, en nuestro caso concreto, la Lengua de Signos Española (en adelante, LSE)- históricamente, han estado reservadas a espacios sociales muy concretos. En ámbito educativo, durante años el uso de esta lengua estuvo prohibido. Tiempo después se crearon colegios específicos para alumnos con déficits auditivos y en la actualidad vivimos en un sistema en el que los alumnos Sordos se encuentran integrados en las escuelas e institutos ordinarios.

En España, la aprobación de la Ley 27/2007, de 23 de octubre, por la que se reconocen las lenguas de signos españolas y se regulan los medios de apoyo a la comunicación oral de las personas sordas, con discapacidad auditiva y sordociegas ha dado lugar a avances tan relevantes como la participación de las personas Sordas ${ }^{1}$ en mayor número de actos sociales a consecuencia de la incorporación de los intérpretes de Lengua de Signos (en adelante, ILSEs) a los eventos sociales. Este hecho lleva aparejado una necesidad de términos en LSE vinculados a materias a las que las personas Sordas no habían accedido con anterioridad. Siendo, por ello, habitual que los ILSEs nos encontremos con carencias -por omisión o incorrección- en los materiales lexicográficos de la LSE.

Es de suma importancia resaltar, en este punto, que las lenguas orales cuentan con medios y recursos para dar a conocer su terminología de forma rápida y eficaz; permanecen de forma escrita y se difunden en los medios de comunicación. En cambio, debido a su carácter visual, los Signos de reciente creación son más complicados de difundir y se divulgan, principalmente a través del contacto entre personas Sordas y/u oyentes, pero de forma mucho más lenta. Aunque, gracias al acceso a Internet y el uso de filmaciones, la difusión de los nuevos Signos es, en la actualidad, más fácil.

De esta necesidad, surge nuestra investigación y el proyecto Mis Manos Hablan ${ }^{\circledR}$ (en adelante, $\mathrm{MMH}$ ) cuyo equipo de investigación ha desarrollado una plataforma online y diversas redes sociales en la que se comparten los resultados del estudio a través de glosarios de temáticas especificas que recogen nuevos Signos para referentes que o no estaban presentes en los materiales lexicográficos de la LSE o si lo estaban no presentaban una relación referente-significado adecuada lingüísticamente.

\section{Fundamentación}

$\mathrm{Al}$ afrontar un proceso educativo hay "dos términos que no debemos ni podemos, necesariamente, desligar del término «educación»: calidad y equidad" (Rodríguez-Martín y Álvarez-Arregui, 2017; p. 5) y, sin lugar a duda, cuando hablamos de la educación del alumnado sordo signante de nuestro país, la calidad y equidad de su formación está ligada a la calidad de los materiales lexicográficos de la LSE. Por otra parte, en relación con la educación inclusiva se deben tener en cuenta

[...] tres interrogantes de gran calado [...]: cómo la entendemos, qué hacemos para lograrla y cómo podemos seguir mejorando nuestras prácticas y comunidades educativas para construir, desarrollar y consolidar entre todas y todos, un verdadero sistema educativo que sitúe el derecho primordial a la diversidad como un eje vertebrador del cambio en los centros educativos. (ibídem)

\footnotetext{
Los estudios sociológicos vinculados a las personas con pérdidas auditivas usan la denominación persona Sorda para hacer referencia a los individuos que se identifican con una comunidad lingüística-cultural, mientras que el concepto sordo/a -con s minúscula- tiene un uso genérico sin connotaciones sociales (Serrat y Fernández-Viader, 2015).
}

En este contexto, cobran especial importancia los estudios lexicográficos y lexicológicos vinculados a la LSE. En el desarrollo profesional del intérprete de LSE, como en el de cualquier intérprete o traductor, tiene gran importancia la preparación previa de las temáticas a tratar durante las interpretaciones y/o traducciones. De este modo, la calidad de los diccionarios y glosarios de la LSE favorecerán el proceso de interpretación y, por ende, el proceso de enseñanza-aprendizaje en las aulas ordinarias por parte del estudiantado sordo signante. Por otra parte, nuestra investigación se centra en individuos cuya primera lengua o L-1 es la LSE. Estos sujetos se caracterizan por presentar, en general, graves problemas de lectoescritura que les limitan el acceso a la información a través de la lectura y/o la lectura labial. Para estas personas, la LSE es la lengua de contacto con el medio que les rodea y de acceso a la información. Por ello, la calidad de los diccionarios y glosarios de la LSE cobra una especial relevancia.

En base a lo dicho, nuestra investigación se caracteriza por un proceso de análisis de las unidades léxicas presentes en los diccionarios y glosarios de la LSE y, el posterior, proceso de elaboración de glosarios temáticos en vídeo. En este proceso debemos tener en cuenta que el signo lingüístico es un fenómeno general, no privativo de los seres humanos ni de su lenguaje, por el cual una señal o expresión perceptible ya sea visual, acústica, táctil... se asocia automáticamente a un significado o contenido (Herrero, 2000). De este modo tanto las palabras como los Signos -unidades léxicas de las lenguas signadas- son signos lingüísticos.

Para De Sausurre el signo lingüístico es una entidad de dos caras -el significante y el significado- que "no une una cosa y un nombre, sino un concepto y una imagen acústica" (De Sausurre, 1945; p. 91) siendo la imagen acústica la representación del objeto o acción que nos dan nuestros sentidos -es lo que pensamos al oír una palabra o ver un Signo- y, en consecuencia, es una imagen sensorial. Por su parte, Pierce en sus Collected Papers -publicados con carácter póstumo, desde 1931 y hasta 1958- nos indica que (cit. en Vázquez, 2010; p. 13)

Un signo esta por algo para la idea que produce o modifica. $\mathrm{O}$ es un vehículo que transporta adentro de la mente algo desde afuera. Aquello por lo que esta se llama su objeto; aquello que transporta, su significado; y la idea a la que da lugar su interpretante.

Independientemente de la visión del signo lingüístico elegida, la de De Saussure o la de Pierce, éste para ser válido debe dar lugar a una imagen acústica, imagen mental o idea-fundamento. Dicho de otra forma, un signo lingüístico, sea una palabra o un Signo, debe evocar en el receptor una imagen en su cerebro; si esto no se produce, el signo estará vacío de significado y no daría lugar a procesos comunicativos.

Para finalizar, debemos mencionar que si por algo se caracteriza el conjunto de personas con déficit auditivo es por su elevada heterogeneidad, la cual, lleva aparejada un gran número de casuísticas y, por tanto: diferentes necesidades comunicativas. En consecuencia, podremos encontrarnos personas con pérdidas auditivas bilingües usuarios de una lengua oral y una signada; individuos monolingües en lengua oral; sujetos usuarios de la lengua oral y con conocimientos de una lengua signada; $y$, personas que emplean la lengua de modalidad viso-gestual y semilingües en lengua oral -como ya indicamos, nuestra investigación se centra en este último tipo de personas con sordera-. Esta elevada heterogeneidad de casuísticas nos lleva a ser partidarios de un sistema educativo que se adapte a las necesidades individuales de cada alumno. En este sentido, en el caso de alumnos signantes que demandan la presencia de un intérprete de LSE para 
acceder a los contenidos curriculares, nos condiciona a investigar en la senda que nos lleve a fomentar un escenario en el que los profesionales de la interpretación cuenten con fuentes bibliográficas que respondan a las necesidades del proceso de enseñanza-aprendizaje y, en consecuencia, del proceso de interpretación.

\section{Objetivos}

Mediante el análisis de los materiales lexicográficos de la LSE, así como la puesta en marcha de un proceso de búsqueda, análisis y creación de neologismos pertenecientes a ámbitos especializados; el objetivo general o principal de nuestra investigación es: Contribuir a que la Lengua de Signos Española (LSE) se adecue a las necesidades y funciones académicas, favoreciendo la labor del ILSE en las aulas y al mismo tiempo, el acceso al curriculum por parte del alumnado Sordos.

Por otra parte, los objetivos específicos son:

- Confirmar la existencia de errores o carencias léxicas en los materiales de la LSE vinculados a ámbitos especializados del saber.

- Establecer un método de trabajo sistematizado y caracterizado por su adecuación a cualquier ámbito o ramas del conocimiento.

- Proponer y difundir neologismos vinculados a ramas especializadas del conocimiento.

- Diseñar materiales audiovisuales -glosarios temáticos en vídeo- que favorezcan el proceso de enseñanza-aprendizaje de vocablos pertenecientes a ramas especializadas del saber y que, mediante el uso combinado de texto e imágenes, favorezcan la asimilación por parte del alumnado sordo de nuevos conceptos.

\section{Metodología}

El proceso llevado a cabo para cada una de las temáticas tratadas durante el proyecto piloto o fase de pilotaje, previa al estudio de los materiales del ámbito científico-técnico de nuestro interés, ha estado constituido por las siguientes ocho etapas o fases (ver Figura 1).

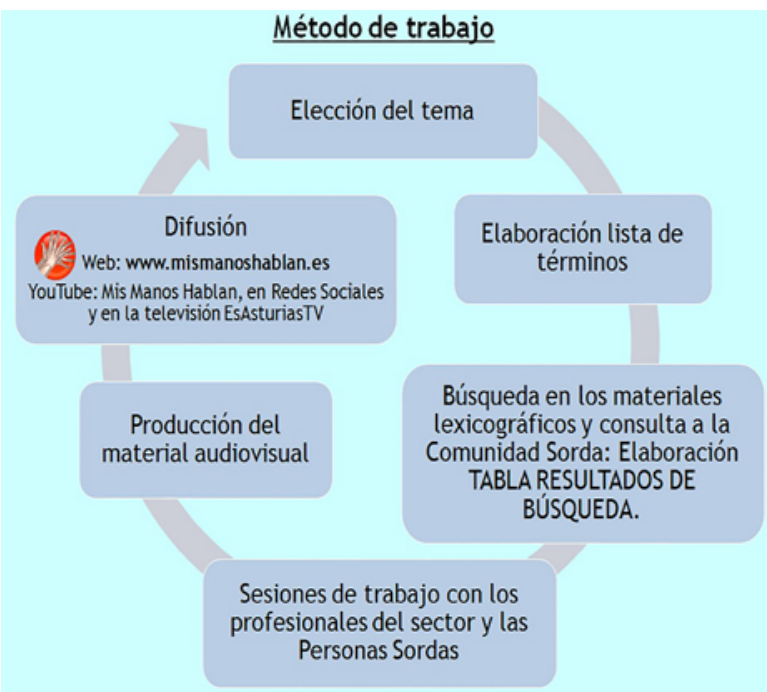

Figura 1. Resumen del método de trabajo Fuente: Valdés, Álvarez y Rodríguez (2017a).
A continuación, se presentará, de forma breve, el trabajo desarrollado en cada una de las etapas (Valdés, 2017 y Valdés, Álvarez y Rodríguez, 2017b):

a) Elección del tema. En esta primera etapa de pilotaje, con el objetivo de establecer un proceso de trabajo sistematizado y conocer las complicaciones que iban a surgir durante su puesta en marcha con el fin de preverlas y solucionarlas, se han elegido temáticas alejadas de nuestro ámbito del saber, que demandan esfuerzo extra de búsqueda y/o consulta en el Diccionario de la Real Academia Española (en adelante, RAE) o con profesionales del sector para, asimilar y/o afianzar los términos en cuestión.

\section{b) Elaboración de una lista de términos.}

c) En caso de necesidad, se realizan contactos presenciales mediante reuniones con profesionales del sector o ámbito tratado. Es de suma importancia que las personas encargadas de transmitir el concepto a las personas Sordas colaboradoras, estén seguras de haber comprendido y asimilado el significado de cada uno de los términos a trabajar. Por ello ante vocablos complicados de entender o con acepciones específicas de un sector, que no aparecen recogidas en el diccionario de la RAE, la consulta con los profesionales es obligada. En el caso de la terminología relativa al ámbito inmobiliario (MMH, 2016c) esta consulta fue primordial y en dos ocasiones. La persona consultada nos indicó lo siguiente:

\begin{tabular}{r|l}
\hline & \multicolumn{2}{c}{ TIPOS DE INMUEBLES } \\
(Bienes que no se pueden mover, lo contrario de muebles) \\
\hline CASA & Vivienda unifamiliar independiente: chalé, palacio, cabaña... \\
EDIFICIO & Viviendas plurifamiliares \\
APARTAMENO & Vivienda pequeña, una habitación \\
PISO & Vivienda grande, con varias habitaciones en una planta. \\
DUPLEX & Vivienda de varias habitaciones en dos plantas \\
ÁTICO & Vivienda con terraza \\
BAJOCUBIERTA & Vivienda situada justo debajo del tejado \\
GARAJE & Espacio para guardar coches \\
TRASTERO & Espacio para guardar cosas \\
OFICINA & Inmueble destinado a negocio urbano, normalmente venta \\
NAVE & Inmueble destinado a servicios: seguros, asesoria, inmobiliaria... \\
SOLAR & Suelo para construir edificios en zona urbana \\
PARCELA & Suelo para construir casas unifamiliares \\
FINCA & Suelo para cultivar \\
\hline
\end{tabular}

Figura 2. Resultado de la consulta con profesionales del ámbito inmobiliario. Fuente: Elaboración propia

d) Búsqueda en los materiales lexicográficos de la LSE diccionarios y glosarios en papel u online- y consulta a propia Comunidad Sorda: personas Sordas, intérpretes de LSE, etc. Los resultados se recogen en una tabla de búsqueda/resultados:

\begin{tabular}{|c|c|c|c|c|c|c|}
\hline \multicolumn{7}{|c|}{ Tema: } \\
\hline \multicolumn{3}{|c|}{$\begin{array}{l}\text { Fecha edición/subida: } \\
\text { Fecha publicación: }\end{array}$} & \multicolumn{4}{|c|}{$\begin{array}{l}\text { Número de Términos Totales: } \\
\text { Número de Neologismos: }\end{array}$} \\
\hline $\begin{array}{l}\text { Término/ } \\
\text { Concepto }\end{array}$ & $\begin{array}{r}\text { Pinedo } \\
(2000)\end{array}$ & $\begin{array}{c}\text { DILSE1.0 } \\
\text { (Fundación } \\
\text { CNSE, 2008) }\end{array}$ & $\begin{array}{l}\text { Glosarios } \\
\text { (VV.AA, } \\
\text { 2002-03) }\end{array}$ & $\begin{array}{l}\text { Web } \\
\text { STS }\end{array}$ & $\begin{array}{c}\text { Web } \\
\text { Sématos }\end{array}$ & MMH \\
\hline & & & & & & \\
\hline & & & & & & \\
\hline
\end{tabular}

Figura 3. Tabla de búsqueda. Fuente: Elaboración propia

Las fuentes consultadas son: el Diccionario de Lengua de Signos Española (Pinedo, 2000), aunque en ocasiones también se recurre a versiones anteriores de este diccionario como son Pinedo (1981 y 1989) y otros materiales lexicográficos (Fernández, 1851; Marroquín, 1975; Fundación CNSE, 2011 y Fundación CNSE, 2013); el Diccionario normativo de la lengua de signos española en su versión 1.0. (Fundación CNSE, 2008); los quince 
glosarios temáticos de la LSE publicados por la Fundación CNSE (VV.AA., 2002-2003) y las páginas web de Spread The Sign -en adelante STS- y Sématos. Además, en la última columna se destina a Mis Manos Hablan-MMH.

Las tablas de búsqueda se han elaborado de forma que el lector en un primer vistazo tenga una idea general de: el número de vocablos encontrados en las fuentes bibliográficas relacionadas con la LSE (aquellos que en la casilla correspondiente tienen algún símbolo); cuántos de ellos presentan problemas lingüísticos al no representar al referente con el que se vinculan (a); que vocablos han requerido la propuesta de un neologismo (N); si la entrada localizada no se corresponde, debido a polisemias, con el significante buscado al pertenecer a otro ámbito del conocimiento (\#); el número de Signos grabados previamente encontrados en las fuentes $(1,2,3 \ldots)$ o si ya conocíamos alguna unidad léxica no recogida en los materiales lexicográficos consultados $(C) \mathrm{o}$, si el Signo se ha encontrado en los materiales lexicográficos en segundas búsquedas (ad), hecho que suele pasar en diccionarios online en continua actualización.

e) Sesiones de trabajo, en las que cada uno de los términos se explica a varias personas Sordas. El proceso seguido depende de la complejidad del vocablo en cuestión y varía desde la simple visualización de una fotografía del objeto o acción en cuestión hasta la explicación reiterada a lo largo de los días con distintos ejemplos y fases de comprobación y aplicación del término.

f) Tras asegurarnos que el concepto se ha entendido, procedemos a comprobar si hemos encontrado un Signo que éste sea correcto y de no serlo o ante vocablos sin Signo procedemos a su creación.

g) Fase de producción del contenido audiovisual, que a su vez se aborda diferentes etapas: Preproducción, producción y postproducción.

h) Subida del contenido a internet/YouTube. Todos los audiovisuales creados se almacenan en nuestro gestor de contenidos de YouTube -canal user/mismanoshablan- para ser publicado y enlazado la web del proyecto y sus redes sociales.

i) Inclusión del vídeo en la página wwww.mismanoshablan. $\underline{\text { es. }}$. La página se ha estructurado en vocabulario, gramática y glosarios. También se ha realizado un sencillo buscador y un menú navegable para buscar términos de una manera cómoda.

j) Difusión. Se lleva a cabo a través de la citada web y varias redes sociales -Facebook, Fanpage de Facebook, Twitter-, google+, blogspot y en una cadena de televisión privada regional.

A pesar de ser la última etapa del proceso, la difusión social es una de las fases más importantes. Coincidimos con Ferreiro y Aroca (2008, p. 1) cuando dicen que la difusión es: "una de las mejores herramientas para la normalización de una lengua", por ello, no hemos escatimado esfuerzos ni recursos en este sentido. La importancia de la difusión a través del mayor número de vías es fundamental no solo para favorecer la transmisión de los neologismos creados sino también para potenciar la sensibilización y conocimiento social de la LSE y la propia Comunidad Sorda.

\section{Resultados y discusión}

A continuación, y a modo de muestra del trabajo llevado a cabo, así como de sus resultados, se presentan algunos ejemplos vinculados al ámbito educativo. Mostraremos las tablas de búsqueda-resultados de tres de las temáticas abordadas durante la fase de pilotaje (océanos, música y vehículos espaciales); pero, solamente desarrollaremos en su totalidad la temática de los océanos (MMH, 2015) y el primer audiovisual creado con vocablos relativos a la música (MMH, 2014d); en el caso del tercer ámbito, los vehículos espaciales (MMH, 2016b), presentaremos -por motivos de espacio- únicamente algunos de los términos estudiados.

\section{Los océanos}

Con el propósito de recoger -o, en su defecto crear- los Signos de los cinco océanos del planeta Tierra se procedió a la búsqueda, en primer lugar, del término océano y a continuación, el Signo de cada uno de los cinco océanos que cubren la superficie terrestre: Atlántico, Pacifico, Índico, Glaciar Ártico y Glaciar Antártico.

La tendencia general observada en los diccionarios y glosarios de la LSE en relación a esta temática es -como se puede comprobar en la tabla de búsqueda/resultados que adjuntamos a continuación- la ausencia de Signos para los diferentes océanos de nuestro planeta. Siendo, en consecuencia, habitual su deletreo.

\begin{tabular}{|c|c|c|c|c|c|}
\hline \multicolumn{6}{|c|}{ Tema: Los Océanos } \\
\hline \multirow{2}{*}{\multicolumn{2}{|c|}{$\begin{array}{l}\text { Fecha edición/subida: } 22 \text { Marzo } 2015 \\
\text { Términos Totales: } 6\end{array}$}} & \multirow{2}{*}{\multicolumn{3}{|c|}{$\begin{array}{l}\text { Fecha publicación: } 18 \text { Mayo } 2015 \\
\text { Neologismos: } 5\end{array}$}} & \multirow[b]{3}{*}{ Sématos } \\
\hline & & & & & \\
\hline Término & Pinedo & $\begin{array}{c}\text { DILSE } 1.0 \\
\text { (F.CNSE, 2008) }\end{array}$ & $\begin{array}{c}\text { Glosarios CNSE, n }{ }^{\circ} 10 \\
\text { (VW.AA., 2002-03) }\end{array}$ & STS & \\
\hline Océano & & & $\sqrt{ }$ & $\sqrt{ }$ & $\sqrt{ }$ \\
\hline Océano Atlántico & & & & a & \\
\hline \multicolumn{6}{|l|}{ Océano Pacifico } \\
\hline \multicolumn{6}{|l|}{ Océano Indico } \\
\hline \multicolumn{6}{|l|}{ Océano Glaciar Ártico } \\
\hline Océano Glacial Antártico & & & & & \\
\hline
\end{tabular}

Figura 4. Tabla de resultados/búsqueda, los océanos. Fuente: Elaboración propia

- Océano

En los diccionarios Pinedo (1981, 1989 y 2000) que forman parte de la biblioteca personal de la investigadora no aparece el vocablo océano. Tampoco se encuentra en el Diccionario Normativo de la Lengua de Signos española (en adelante, DILSE) ni en su versión en CD-ROM ${ }^{2}$ (Fundación CNSE, 2008) ni en su versión en papel (Fundación CNSE, 2011) ni en el diccionario visual LSE-español-inglés (Fundación CNSE, 2013).

La entrada océano, se localiza en el glosario n ${ }^{\circ} 10$ de la Fundación CNSE (Aroca et al., 2002, p. 76) dedicado a la geografía. Por su parte, las webs de STS y Sématos también proporcionan una búsqueda exitosa. En las tres fuentes se muestra el mismo Signo (ver Figura 5).
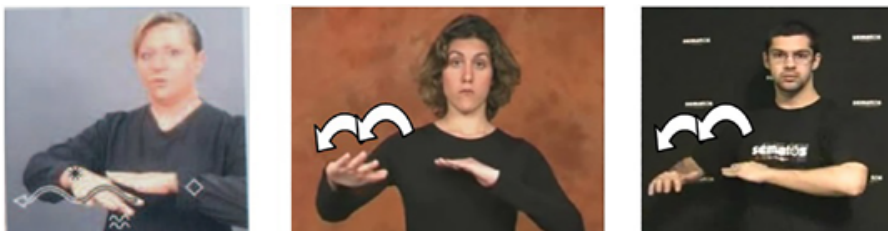

Figura 5. OCÉANO. ${ }^{3}$ Fuente: Aroca et al. (2002, p. 76), STS y Sématos.

OCÉANO en LSE es un Signo bimanual, en el que la mano pasiva adquiere una configuración B estática -que representa la costa- mientras que la mano activa o dominante abierta y con todos los dedos extendidos dibuja un movimiento ondulatorio al tiempo que se aleja de la mano pasiva -simulando olas que se alejan de la línea de costa-. Este Signo, a pesar de ser una unidad

\footnotetext{
2 Este diccionario, a día de hoy, es un material obsoleto al ser solamente compatible con Windows 2000, XP, Me y Vista tal como indica la guía de uso que acompaña al CD-ROM.
} 
léxica normalizada y ampliamente conocida por la Comunidad Sorda no aparece en los materiales lexicográficos de la LSE hasta el año 2002, hecho que nos llama la atención, por ello hemos llevado a cabo una nueva consulta: mar.

Para el vocablo mar, las ocho fuentes bibliográficas consultadas -ver figura 6- nos proporcionan el mismo Signo: éste, se diferencia del de OCÉANO únicamente en el parámetro del movimiento de la mano dominante, que en esta ocasión sigue una trayectoria recta hacia adelante.

La diferencia detectada en la presencia de los Signos MAR y OCÉANO en los diccionarios y glosarios de la LSE, nos llevó a buscar ambos términos en dos fuentes anteriores: Diccionario usual de mímica y dactilología (Fernández, 1851) y El lenguaje mímico (Marroquín, 1975). En el primero, encontramos solamente mar; mientras que, en el segundo, no hay entrada para ninguno de los dos vocablos. En el diccionario de Villabrille podemos leer: "MAR: Con las dos manos estendidas, unidad y con las palmas hácia abajo, se imita el movimiento de las olas y despues se tiende el brazo á una grande estension" (Fernández, 1851; p. 98).

A pesar, de que ambas unidades léxicas -MAR y OCÉANOson diferentes, resulta cuanto menos llamativo y curioso el hecho de que uno de ellos aparece ya en el año 1851 -MAR-y, OCÉANO no queda recogido hasta el siglo XXI, en el glosario específico de geografía.

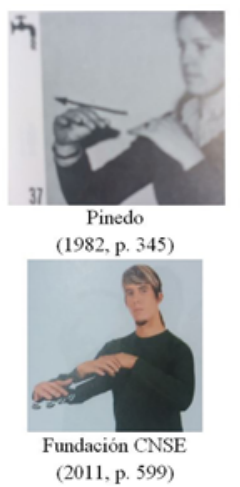

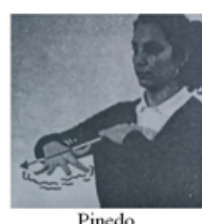

(1989, p. 476)

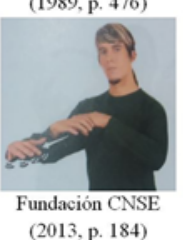

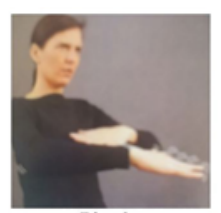

Pinedo (2000, p. 559)

STS

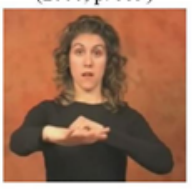

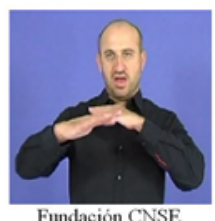

Fundación CNSE (2008)

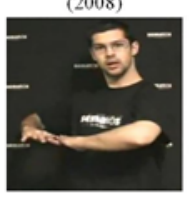

Sématos
Figura 6. MAR. Fuente: Adaptado de Pinedo (1982, 1989, y 2000), Fundación CNSE (2008, 2011 y 2013), STS y Sématos.

Por otra parte, en relación con el nombre de cada uno de los océanos, la consulta de las fuentes solamente nos proporcionó una propuesta para océano Atlántico en STS. Además, en la misma página web se detecta una tercera entrada -junto con OCÉANO y OCÉANO.ATLÁNTICO- bajo la denominación: océano mundial/ océano global.
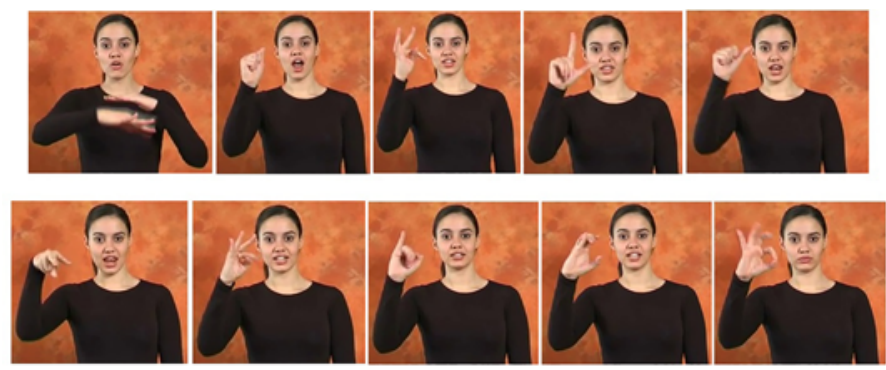

Figura 7. OCÉANO.ATLÁNTICO. Fuente: STS

\footnotetext{
${ }^{3}$ Cuando hacemos referencia a un Signo, esto es de un signo lingüístico de la Lengua de Signos Española (LSE) u otra Lengua de Signos, lo escribiremos en mayúscula. Por consiguiente con "PERRO" estamos haciendo referencia al Signo en LSE del término del español "perro".
}

En la Figura 7 se observa que la propuesta de STS para océano Atlántico consiste en signar OCÉANO y a continuación haciendo uso del alfabeto dactilológico empleado por la Comunidad Sorda española deletrear: A-T-L-A-N-T-I-C-O.

El deletreo o empleo de la dactilología es un recurso utilizado en el ámbito de la educación de las personas Sordas que introdujeron los educadores oyentes. Sus usos más habituales, son (Rodríguez, 1991; Herrera, 2005; Fernández 2008 y Chapa, 2000): deletrear los nombres propios de personas o lugares; deletrear palabras para las cuales no existe Signo; acompañar a un Signo desconocido por el receptor, por ejemplo para superar diferencias o modificaciones entre unidades léxicas empleadas por signantes diferentes, producir eufemismos y crear nuevos Signos -en combinación con otros parámetros- aportando la configuración de la mano.

Por otra parte, la dactilología es un recurso que no puede considerarse un método de creación de neologismos -del mismo modo que, para una lengua oral, deletrear una palabra no es sinónimo de acuñar un nuevo vocablo- ni para transmitir información a una persona Sorda. El abuso de la dactilología, dejará a las personas exclusivamente signantes en una situación de desventaja (Tavares, Ferreira y Lima, 2010). Por tanto, no se puede considerar la propuesta de STS como una opción válida de Signo para OCÉANO-ATLÁNTICO sino un mero deletreo de una palabra -en concreto un nombre propio- y se procede a la creación de nuevos Signos para cada uno de los océanos.

Los neologismos propuestos para los océanos se crean por el método denominado Signo-Nombre, del mismo modo que se proponen los Signos de cada uno de los individuos que forman parte de la Comunidad Sorda: a partir de un rasgo distintivo, en este caso la forma o localización de cada uno de los océanos. Además, antes de la realización de cada una de las unidades que se muestran en Figura 8, se signará: OCÉANO.

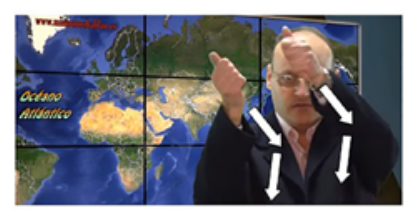

ATLÁNTICO

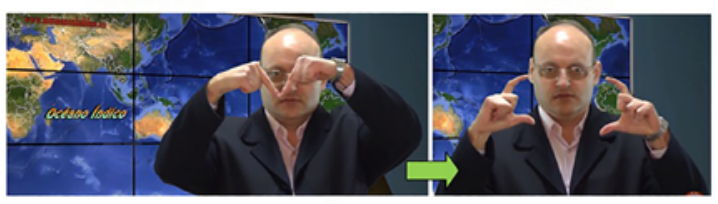

ÍNDICO

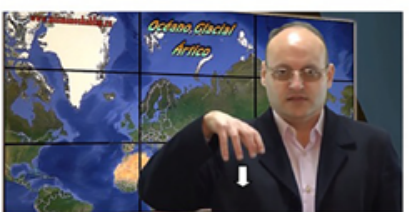

GLACIAL.ÁRTICO

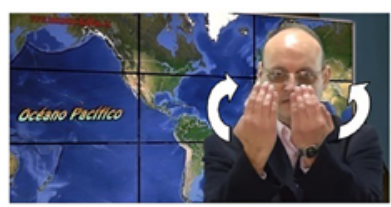

PACIFICO

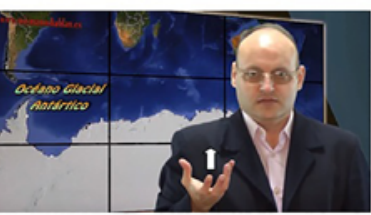

GLACIAL.ANTÁRTICO
Figura 8. Neologismos para los océanos. Fuente: $M M H(2015){ }^{4}$

Debemos añadir, que los neologismos presentados no se usarán en todas las ocasiones. Así por ejemplo, en ámbito educativo se recurrirá al uso de la dactilología durante un examen de geografía en el que los alumnos deban poner el nombre en un mapa mudo a cada uno de los océanos; como consecuencia de que, los Signos propuestos darían "pistas" a los alumnos Sordos. 


\section{Música}

Para la elaboración del material audiovisual creado ${ }^{9}$ necesitamos la colaboración de varios profesionales del ámbito musical y además fue necesario consultar bibliografía específica para definir algunos de los términos o vocablos.

En la Figura 9, se muestra al lector la tabla de búsqueda-resultados para los vocablos trabajados: Lenguaje musical, atril, afinador, metrónomo, batuta, instrumento, músico, director, composición, partitura, particela, pentagrama, clave, compás y notas musicales.

\begin{tabular}{|c|c|c|c|c|c|c|c|}
\hline & $\begin{array}{l}\text { edición: } 12 \text { Abril } 201 \\
\text { os Totales: } 15\end{array}$ & & $\begin{array}{l}\text { Tema: } \\
\text { cha publicación: } \\
\text { ologismos: } 11\end{array}$ & lúsica & & & \\
\hline & & & & Colaborac & ylo ase & lento: Mus: & incipado \\
\hline & $\frac{\text { Términol }}{\text { concepto }}$ & $\frac{\text { Pinedo }}{(2000)}$ & $\begin{array}{c}\text { DILSE 1.0 } \\
\text { (F.CNSE, 2008) }\end{array}$ & (W.AA., 2002.03) & STS & Sématos & MMH \\
\hline 1 & Lenguaje musical & & & & & & $\mathrm{N}$ \\
\hline 2 & Atril & $\sqrt{ }$ & & & $\sqrt{1}$ & $\sqrt{ }$ & $1+\mathrm{N}$ \\
\hline 3 & Afinador & & & & & & $\mathrm{N}$ \\
\hline 4 & Metrónomo & & & & 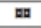 & & 1 \\
\hline 5 & Batuta & & & & & & $\mathbf{N}$ \\
\hline 6 & Instrumento & & & & $\sqrt{ }$ & & 1 \\
\hline 7 & Músico & & & & $\sqrt{ }$ & & 1 \\
\hline 8 & Director & a & a & & a & & $\mathrm{N}$ \\
\hline 9 & Composición & & & & & & $\mathrm{N}$ \\
\hline 10 & Partitura & & & & $a$ & & $\mathbf{N}$ \\
\hline 11 & Particela & & & & & & $\mathrm{N}$ \\
\hline 12 & Pentagrama & & & & & & $\mathrm{N}$ \\
\hline 13 & Clave & & & & & & $\mathrm{N}$ \\
\hline 14 & Compás & 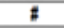 & $\#$ & & $\#$ & & $\mathrm{~N}$ \\
\hline 15 & Notas musicales & & & & $m$ & & $\mathrm{~N}$ \\
\hline
\end{tabular}

Figura 9. Tabla de resultados/búsqueda, música. Fuente: Elaboración propia

\section{- Lenguaje musical}

Por combinación secuencial de: LENGUAJE+MÚSICA, se obtiene una propuesta de neologismo para el término lenguaje musical, no recogido anteriormente en las fuentes.

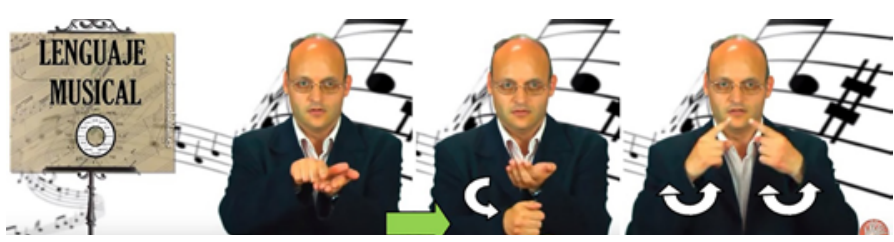

Figura 10. Neologismo LENGUAJE.MUSICAL. Fuente: MMH (2014d)

\section{- Atril}

Soporte "de madera o metal que sirve para sostener papeles o libros abiertos y leer en ellos con comodidad" (Pedrell, 2009; p. 32). En Pinedo (2000), STS y Sématos se localizan entradas similares para este término; tal y como se puede comprobar a continuación:
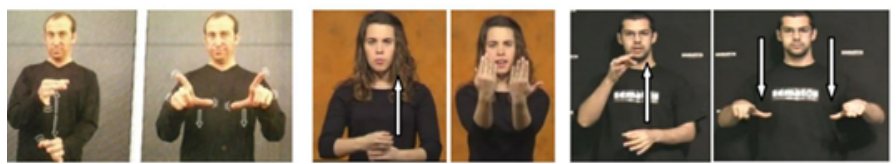

Figura 11. ATRIL. Fuente: Adaptado de Pinedo (2000, p. 174), STS y Sématos

En esta propuesta seguimos la estructura empleada en MMH (2016a) para TRÍPODE+CÁMARA.VÍDEO, TRÍPODE+CÁMARA. FOTOS, TRÍPODE+FOCO, la empleada

\footnotetext{
${ }^{4}$ En todos los materiales audiovisuales creados por Mis Manos Hablan ${ }^{\circledR}$ aparece José Manuel Valdés.
}

para TRÍPODE+CUADRO (MMH, 2014a), etc. obteniéndose la combinación secuencial: TRÍPODE+CL "Forma rectangular del soporte"+MÚSICA. De este modo, mediante el mecanismo de creación léxica denominada nombre clasificatorio, partiendo del Signo TRÍPODE se puede hacer referencia a cualquier estructura de tres patas que sirva para sujetar o apoyar algo.

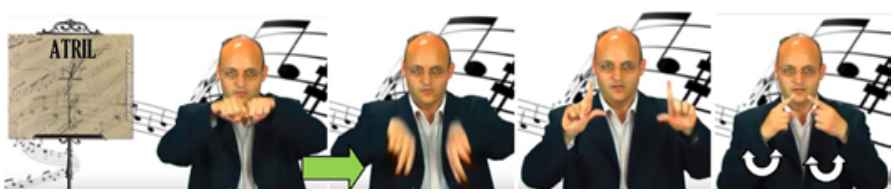

Figura 12. Neologismo ATRIL. Fuente: $\mathrm{MMH}$ (2014d)

\section{- Afinador}

Instrumento empleado para afinar los instrumentos musicales por lo que nos "permite cantar o tocar entonando con perfección los sonidos" (RAE, 2018), es decir, controlar el sonido o afinación de las notas musicales. Empleando Signos de la LSE proponemos la estructura: NOTAS. MUSICALES+SONIDO+ CONTROLAR, pudiendo obviar el primer Signo.
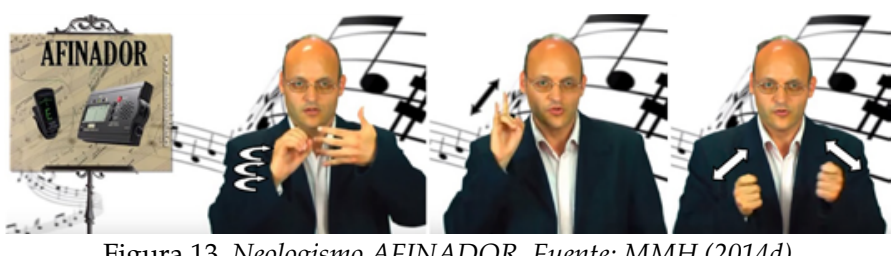

Figura 13. Neologismo AFINADOR. Fuente: $M M H$ (2014d)

\section{- Metrónomo}

Es el instrumento o "máquina, a manera de reloj, para medir el tiempo e indicar el compás de las composiciones musicales" (RAE, 2018). Únicamente en STS se encuentra un Signo para metrónomo. En una primera búsqueda no se localizó esta propuesta, por lo que es de suponer que se incluyó en la web en el tiempo trascurrido desde nuestra primera búsqueda (en abril del 2014) y la llevada a cabo para elaborar este artículo (mayo de 2020). La entrada de STS coincide con la grabada en nuestro primer vídeo dedicado a la música (MMH, 2014).
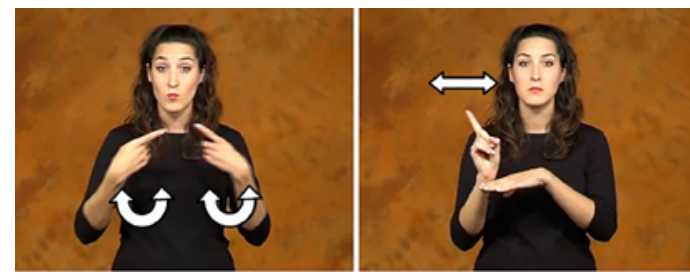

Figura 14. METRÓNOMO. Fuente: STS

\section{- Batuta}

La battuta -en italiano- o batuta, en su "voz españolizada por el uso, equivalente a compas, medida. También se da este nombre a una especie de baquetilla con que los directores de orquesta marcan el compás, indican los movimientos y señalan la entrada de ciertos instrumentos o voces" (Pedrell, 2009; p. 48). El uso de una referencia para un objeto fino y alargado; y, a continuación, manteniendo la misma configuración empleada, imitando el movimiento realizado por un director durante la dirección se obtiene un neologismo para batuta que recogemos en la Figura 15. 


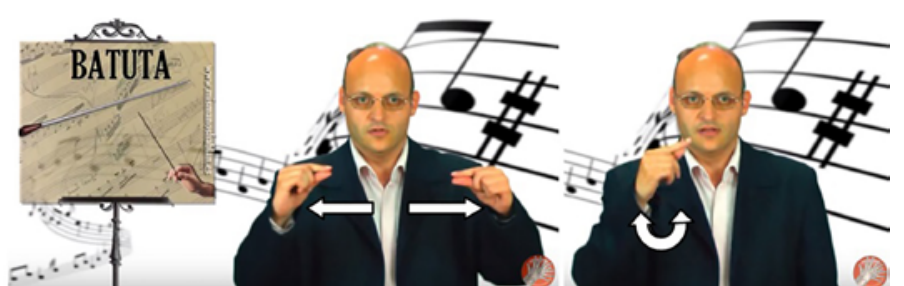

Figura 15. Neologismo BATUTA. Fuente: MMH (2014d)

\section{- Instrumento}

Se define instrumento musical como aquel "objeto compuesto de una o varias piezas dispuestas de modo que sirva para producir sonidos musicales" (RAE, 2018). En otras palabras es una "cosa" para hacer música: COSA+MÚSICA.

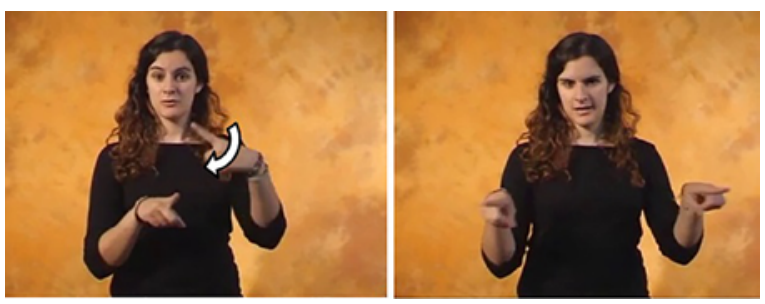

Figura 16. INSTRUMENTO. Fuente: STS

\section{- Músico}

Mediante el procedimiento de nombre clasificatorio se obtiene la combinación: PERSONA+MÚSICA localizada en STS y que se muestra en la figura 17.

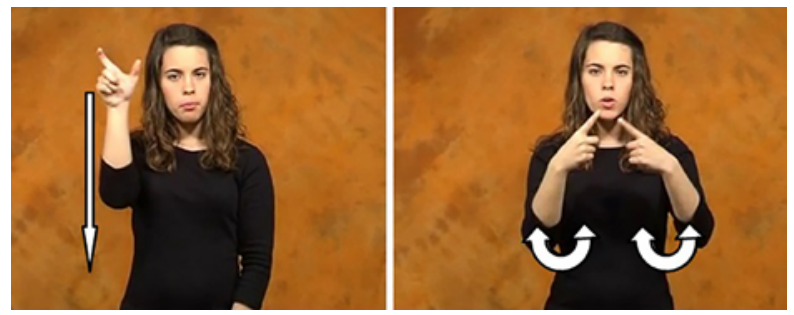

Figura 17. MÚSICO. Fuente: STS

\section{- Director}

Este vocablo aplicable a gran variedad de ámbitos, se encuentra dentro de la jerga relativa a la música en diferentes voces: director de orquesta, director de coros, director de un conservatorio, director de una banda, director de un teatro... En el diccionario Pinedo (2000) y en el DILSE 1.0 (Fundación CNSE, 2011) se presenta el término genérico, sin vinculación con el ámbito musical. Se observan dos Signos diferentes o variaciones geográficas y/o temporales -Figura 18-.
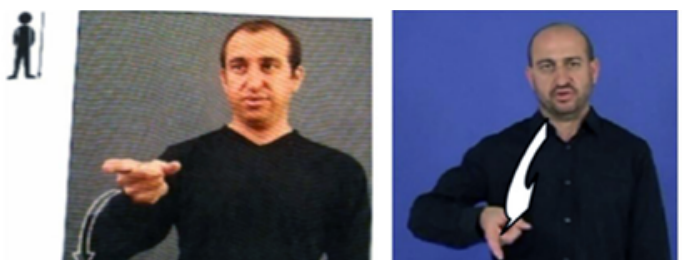

Figura 18. DIRECTOR. Fuente: Adaptado de Pinedo $(2000,358)$ y Fundación CNSE $(2011,350)$

El director de orquesta es (Pedrell, 2009; p. 138): la persona "que dirige la [orquesta] de un teatro, un concierto, una capilla, etc.".
Siendo la orquesta, el "conjunto de músicos que interpretan obras musicales con diversos instrumentos y bajo la guía de un director" (RAE, 2018).

A partir de las definiciones anteriores se concluye que la entrada: director de orquesta de STS -Figura 19- no sería correcta al asignar: GRUPO+MÚSICA a orquesta. La orquesta es un tipo concreto de agrupación musical; por lo que, estamos ante una generalización de un término que elimina su matiz diferenciador: existencia de director.
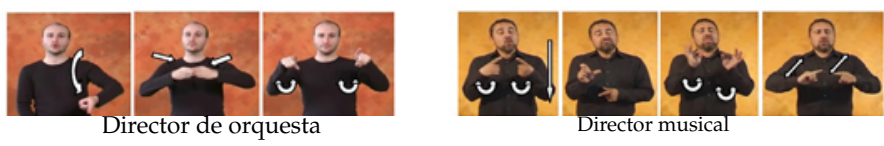

Figura 19. DIRECTOR.DE.ORQUESTA/DIRECTOR.MUSICAL Fuente: STS

Por otro lado, la entrada director musical de STS emplea: MÚSICA+PERSONA+CL "movimiento batuta"+DIRIGIR, cae en un tópico muy habitual: que todos los directores emplean batuta. Nuestra propuesta es: PERSONA+DIRIGIR+GRUPO+MÚSICA. En la Figura 20 se recogen los tres últimos Signos, a ellos se puede anteponer la unidad PERSONA, en función del contexto.

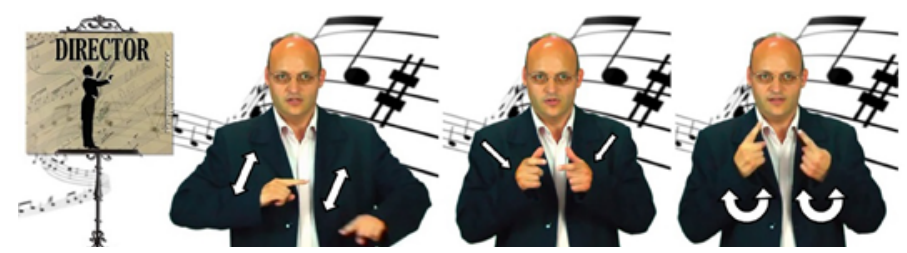

Figura 20. Neologismo DIRECTOR. Fuente: MMH (2014d)

\section{- Composición musical}

Este vocablo hace referencia a cualquier tipo de obra musical. Estas, se pueden clasificar en composiciones de tipo: vocal, instrumental o vocal-instrumental. La primera se escribe para voces solas; la instrumental, se divide en música de orquesta y música de cámara; y, la vocal-instrumental presenta cuatro divisiones: música sagrada, dramática, de cámara y aires o melodías populares (Pedrell, 2009). Nuestra propuesta de neologismo se centra en la definición general de una composición como: obra musical, MÚSICA+VER. PRINCIPIO. FIN.

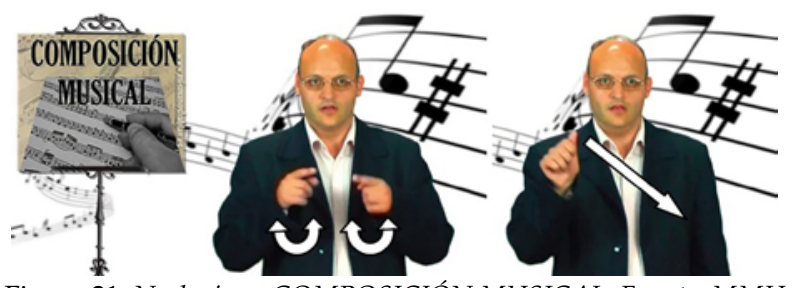

Figura 21. Neologismo COMPOSICIÓN.MUSICAL. Fuente: MMH (2014d)

\section{- Pentagrama}

Se denomina pentagrama: "a las cinco líneas sobre las que se escribe la música" (SDM, 1979; p. 11). En él se distinguen, además, de las cinco líneas, cuatro espacios que se cuentan de arriba abajo. Proponemos dos neologismos: 1) Signo en el que la mano dominante adquiera una configuración 5, partiendo de posición paralela al pecho del signante y una orientación con la palma hacia afuera, realiza un giro de muñeca para finalizar describiendo una trayectoria recta; o, 2) las dos manos en 5, se mueven de forma simétrica una hacia izquierda y la otra a la derecha. 

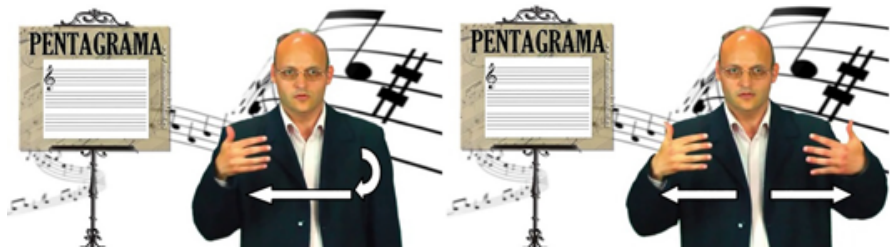

Figura 22. Dos neologismos para PENTAGRAMA. Fuente: MMH (2014d)

\section{- Partitura}

Es el "libro o cuaderno de música en que están escritas, en pentagramas superpuestos, todas las partes instrumentales o vocales de una composición para coros o para orquestas" (De Candé, 2002; p. 388). Es habitual que se hable de "la partitura" de una obra musical, cuando se debería hablar del "libro" o el "cuaderno" de la obra en cuestión (ibídem).

En STS encontramos una paráfrasis -o explicación, no un Signo, que no hace referencia a ningún valor con carácter diferenciador y que podría interpretarse como: "escribir en un libro de música" dando lugar a la confusión- compuesta por cinco unidades léxicas, que se muestran en la Figura 24: MÚSICA+LIBRO. ABRIR+TEXTO+ESCRIBIR+++TEXTO++:

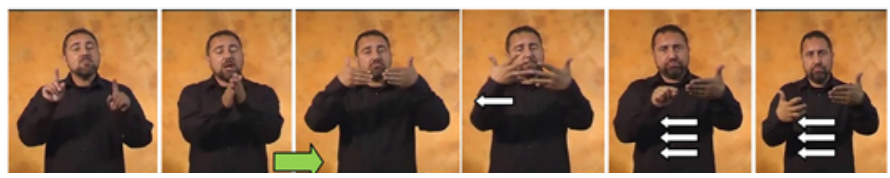

Figura 23. Ejemplo de búsqueda, PARTITURA. Fuente: STS

Se puede decir que la partitura es: INSTRUMENTO+ PENTAGRAMA+++GRUPO o el conjunto de todos los pentagramas que, de forma individual, corresponden a todos -el grupo completo- los instrumentos que intervienen en una composición musical.

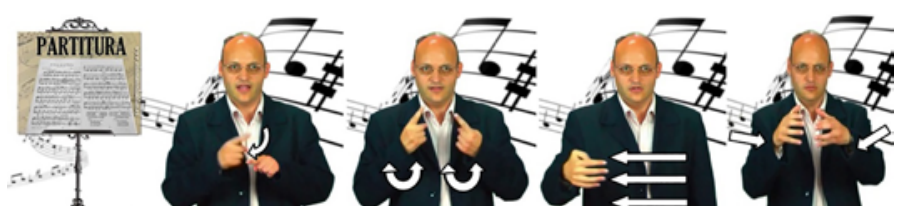

Figura 24. Neologismo PARTITURA. Fuente: $\mathrm{MMH}$ (2014d)

\section{- Particela}

Se denomina particela, a la parte de la composición que le corresponde a cada instrumento o voz; en otras palabras el conjunto de todas las particelas conforman la partitura de la pieza musical completa.

Por ello, siguiendo la misma estructura empleada en el neologismo propuesto para partitura tenemos: INSTRUMENTO + PENTAGRAMA+++CADA.UNO, al ser la particela el grupo de pentagramas que le corresponde a cada instrumento.

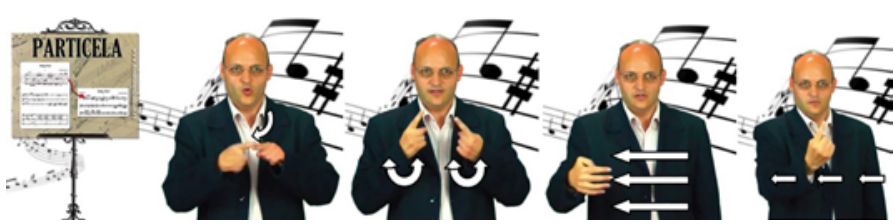

Figura 25. Neologismo PARTICELA. Fuente: MMH (2014d)

\section{- Clave}

Es el "signo que se coloca al principio del pentagrama para precisar la altura de unas de las líneas, donde empieza el trazo de la clave" (De Candé, 2002; p. 374). Además, "determina el nombre que deben tener las notas en el pentagrama" (SDM, 1979; p. 17) de la siguiente forma: "partiendo de la nota a la que da su nombre la clave, por el orden ascendente o descendente de la serie, se conoce el lugar que ocupan las demás notas en el pentagrama y en las líneas y espacios adicionales" (SDM, 1979; p. 17). Reciben, también el nombre de llaves: "metafóricamente hablando se ha dicho que abren la puerta de una pieza de canto" (Pedrell, 2009; p. 98).

Las claves son siete: la clave de sol, sobre la segunda línea, de abajo arriba; las claves de fa (en la tercera o la cuarta línea) y las claves de do (en la primera, segunda, tercera o cuarta línea) -en la imagen que acompaña al neologismo propuesto para CLAVE. MUSICAL, ver Figura 26, se pueden ver la clave de sol, dos claves de do y una de las claves de fa existentes-.

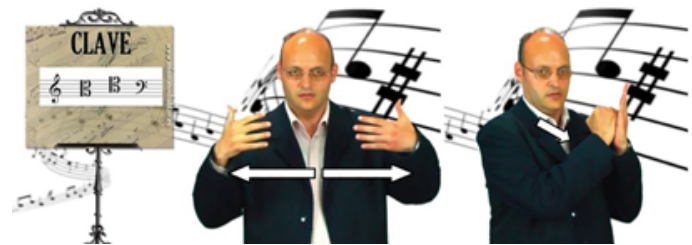

Figura 26. Neologismo CLAVE.MUSICAL. Fuente: MMH (2014d)

En definitiva, la clave musical: es una marca que se coloca al inicio del pentagrama por lo que el neologismo propuesto es: PENTAGRAMA+MARCA.

\section{- Compás}

De la Vega y García-Palao (2008; p. 29) definen compás como "la organización del ritmo en unidades periódicas de tiempo" y añaden que, también, puede hacer referencia a: "cada una de las divisiones del pentagrama en que se representan estos períodos de tiempo separados por líneas divisorias".
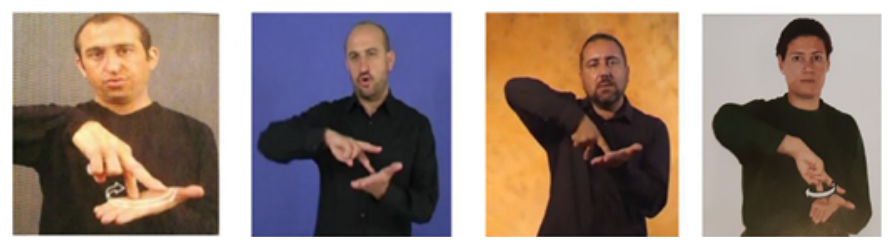

Figura 27. COMPÁS. Fuente: Adaptado de Pinedo (2000, p. 291), Fundación CNSE (2008), STS y Fundación CNSE $(2011,268)$.

La unidad léxica encontrada en las cuatro fuentes indicadas y recogidas en la Figura 27 hacen referencia al instrumento empleado para trazar circunferencias. No se ha encontrado ningún Signo vinculado al término compás referido a la música. Por tanto, se procede a su creación:

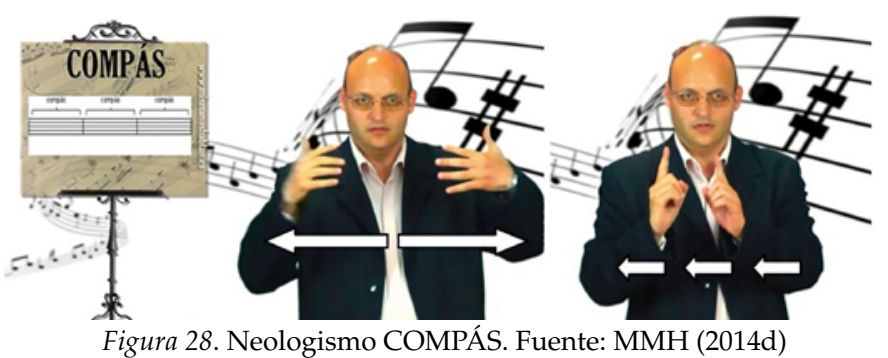




\section{- Notas musicales}

En STS, en la entrada nota musical se observa repetición. Por tanto, dicha propuesta debería asociarse con el plural NOTAS. MUSICALES y para el género singular eliminar el movimiento. Además, el Signo PENTAGRAMA -que se signaría antes que la unidad léxica de NOTA.MUSICAL o, en plural, NOTAS. MUSICALES- solamente se debería omitir en una situación en la que no dé lugar a dudas de significado.

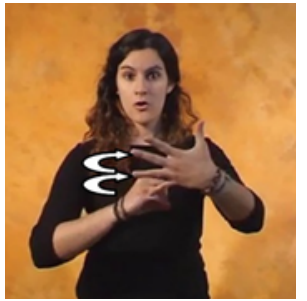

Figura 29. NOTA.MUSICAL. Fuente: STS

Nuestra propuesta sería: realizar el Signo PENTAGRAMA y a continuación un clasificador para nota musical que se repetiría varias veces para el término en plural.

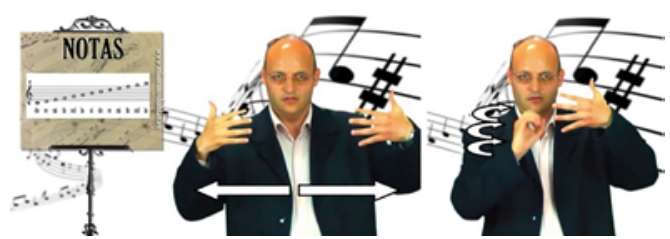

Figura 30. Neologismo NOTAS.MUSICALES. Fuente: MMH (2014d)

En relación con las notas musicales, hemos grabado el denominado método Kodály -o fononimias de Kodály- empleado con niños y por el cual se asigna a cada una de las notas un gesto o configuración de la mano. Al igual que se usa con niños oyentes, este método puede ser aplicado con niños y jóvenes Sordos en las aulas de música. Recogemos dicho método, a continuación:

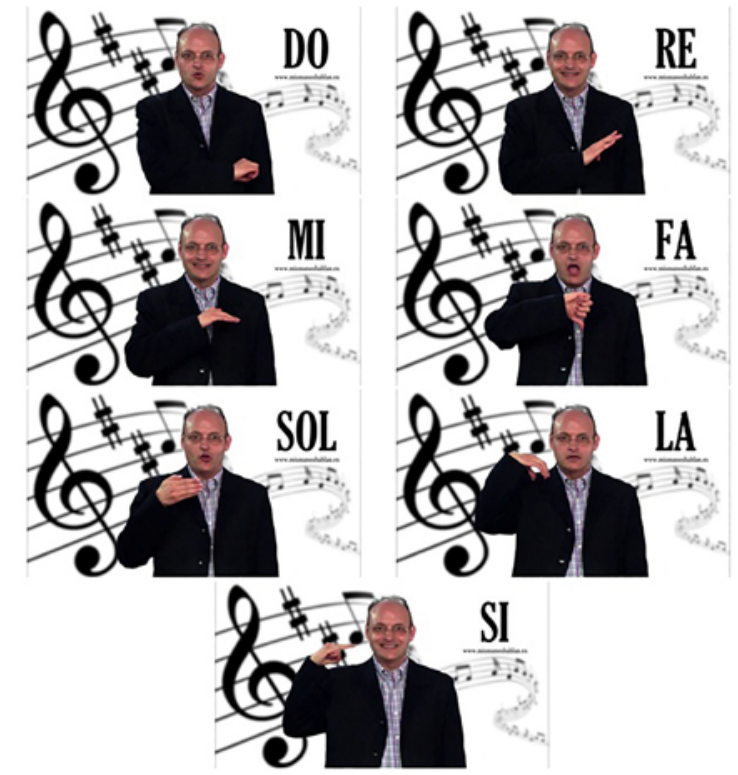

Figura 31. Método Kodaly: DO, RE, MI, FA, SOL, LA, SI. Fuente: $M M H$ (2014c)

\section{Vehículos espaciales}

El último de los temas abordados en este artículo hace referencia a las naves espaciales y otros términos relacionados con el espacio. En esta ocasión, el análisis se llevará a cabo para aquellos vocablos localizados en los materiales lexicográficos de los LSE y que presenten incongruencias lingüísticas -aparecen subrayados en la tabla de resultados- y el resto, neologismos de creación propia, se pueden visualizar en el material difundido.

\begin{tabular}{|c|c|c|c|c|c|c|c|}
\hline \multicolumn{3}{|c|}{$\begin{array}{l}\text { Focha edición/subida: } 28 \text { Marzo } 2015 \\
\text { Términos Totales: } 21\end{array}$} & \multicolumn{5}{|c|}{$\begin{array}{l}\text { Tema: Vehieulos espaciales y otros del espacio } \\
\text { Fecha publicación: } 17 \text { Marzo } 2016 \\
\text { Neologismos: } 18\end{array}$} \\
\hline & Término & $\frac{\text { Pinedo }}{(2000)}$ & (F.CNSE, 2008) & WV.A. Al., 2002.03) & STS & Sématos & ММH \\
\hline 1 & Astronomia & $\not x$ & & & $\not$ & प्र & $\mathrm{N}$ \\
\hline 2 & Astronauta & v & & & $v$ & $v$ & $1+$ \\
\hline 3 & Telescopio & $v$ & 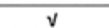 & & $v$ & & 1 \\
\hline 4 & Tormenta Solar & & & & & & $\mathrm{N}$ \\
\hline 5 & Polvo cósmico & & & & & & $\mathrm{N}$ \\
\hline 6 & Agujero negro & & & & & & $\mathrm{N}$ \\
\hline 7 & Agujero de gusano & & & & & & $\mathrm{N}$ \\
\hline 8 & Nave espacial & & & & & & $\mathrm{N}$ \\
\hline 9 & Sonda espacial & & & & & & $\mathrm{N}$ \\
\hline 10 & Satedilite artificial & & & & 무 & & $\mathrm{N}$ \\
\hline 11 & Transbordador & & & & & & $\mathrm{N}$ \\
\hline 12 & Estación orbital & & & & & & $\mathrm{N}$ \\
\hline 13 & Cohete & $\not \mathbf{x}$ & & & $v$ & 무 & 1 \\
\hline 14 & Capsula & & & & & & $\mathrm{N}$ \\
\hline 15 & Viaie espacial & & & & 只 & & $\mathrm{N}$ \\
\hline 16 & $\begin{array}{l}\text { Robot de } \\
\text { exploración }\end{array}$ & & & & & & $\mathrm{N}$ \\
\hline 17 & Velas solares & & & & & & $\mathrm{N}$ \\
\hline 18 & Alunizajo & & & & & & $\mathrm{N}$ \\
\hline 19 & Basura espacial & & & & & & $\mathrm{N}$ \\
\hline 20 & Lanzamiento & & & & & & $\mathrm{N}$ \\
\hline 21 & Escafandra & & & & & & $\mathrm{N}$ \\
\hline
\end{tabular}

Figura 32. Tabla de resultados/búsqueda, vehículos espaciales y otros del espacio. Fuente: Elaboración propia

\section{- Astronomía}

La astronomía es "la ciencia que trata de los astros, de su movimiento y de las leyes que lo rigen" (RAE, 2018). Por otra parte, un astro es cualquier cuerpo con forma definida: satélites, cometas, meteoros, planetas... A partir de la definición anterior, podemos concluir que en las tres opciones encontradas -Pinedo (2000), STS y Sématos- echamos en falta que se siga el método de formación de nuevos Signos denominado nombre clasificatorio partiendo de CIENCIA.
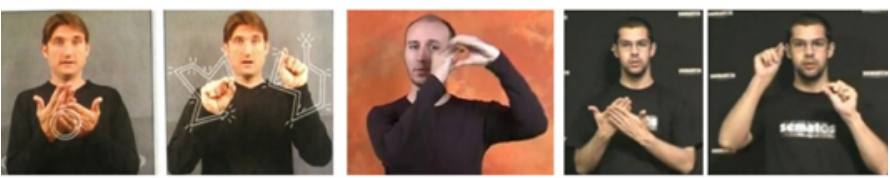

Figura 33. Ejemplo de búsqueda, ASTRONOMÍA.

Fuente: Adaptado de Pinedo (2000, p. 166), STS y Sématos.

En STS encontramos una entrada para astronomía que coincide con la unidad léxica TELESCOPIO. Por tanto, nos encontramos ante un caso de polisemia -un mismo Signo lingüístico empleado con distintos significados- que en el caso de la creación y/o propuesta de neologismos debe evitarse. Pinedo (2000) y Sématos coinciden y muestran la combinación secuencial: ESTUDIAR+ASTRO. Si entendemos la ciencia como un estudio, se podría considerar una fórmula válida; pero, consideramos que la ciencia va más lejos de un simple estudio. Por ello, no entendemos un Signo para astronomía en el que no aparezca el Signo: CIENCIA. 

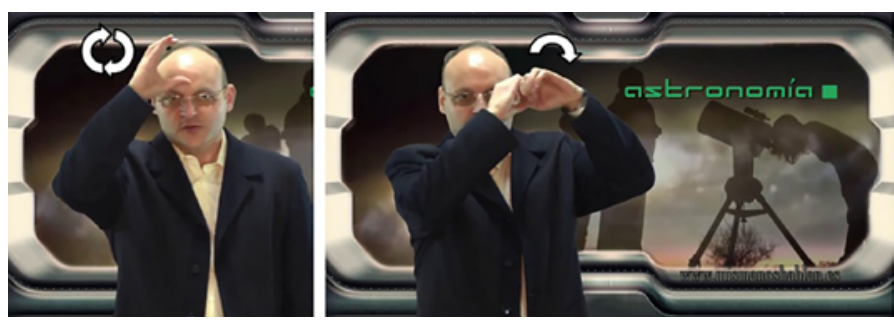

Figura 34. Neologismo, ASTRONOMÍA. Fuente: MMH (2016b)

Ante las evidencias detalladas se propone la combinación: CIENCIA+TELESCÓPIO. Por ser la astronomía una ciencia que estudia los astros y para ello, de forma general, debe hacer uso de los telescopios.

\section{- Astronauta}

Las tres versiones encontradas coinciden en emplear la unidad: COHETE. Pinedo (2000) recoge la combinación: PERSONA+COHETE; STS, sustituye el Signo PERSONA por otro que referencia la acción de ponerse un casco; y, por su parte, Sématos nos proporciona la secuencia de tres Signos, que indicamos a continuación: PERSONA+TRABAJO+COHETE.
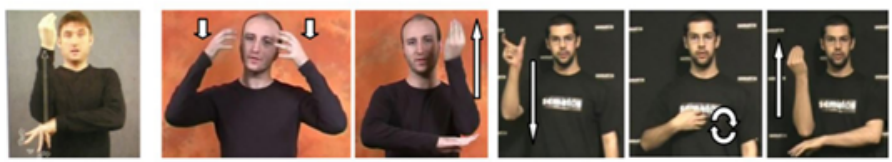

Figura 35. Ejemplo de búsqueda, ASTRONAUTA

Fuente: Adaptado de Pinedo (2000, p. 166), STS y Sématos.

Las tres propuestas recogidas pueden considerarse válidas durante una interpretación. Pero, al ser opciones recogidas en materiales lexicográficos de la LSE consideremos que deben mejorarse -al menos, la segunda y la tercera-. En el caso de STS, no sigue el método, denominado nombre clasificatorio, empleado para la mayoría de profesiones y Sématos, por su parte, emplea el Signo TRABAJAR que en dicho procedimiento tampoco se usa. Además, el Signo TRABAJAR que se emplea no hace referencia al verbo trabajar o al sustantivo trabajo sino que significa: cuesta trabajo o esfuerzo. En el material audiovisual elaborado hemos recogido la siguiente variación: PERSONA+CASCO+COHETE en la que el segundo Signo se puede eliminar dando lugar a la opción más simple: PERSONA+COHETE, que coincidiría con la de Pinedo (2000).

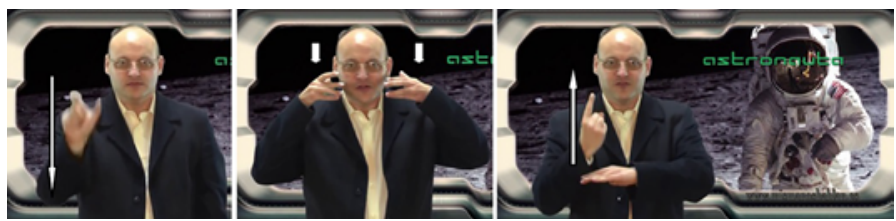

Figura 36. Neologismo, ASTRONAUTA. Fuente: MMH (2016b)

\section{- Satélite artificial}

STS nos proporciona la combinación: TIERRA+CL "planeta" $+C L$ "satélite girando". Esta opción emplea el Signo TIERRA -en su acepción "Material desmenuzable de que principalmente se compone el suelo natural" (RAE, 2018)- para PLANETA.TIERRA, cuando nuestro planeta tiene un Signo propio. Por ello, no consideramos que sea un Signo acertado.

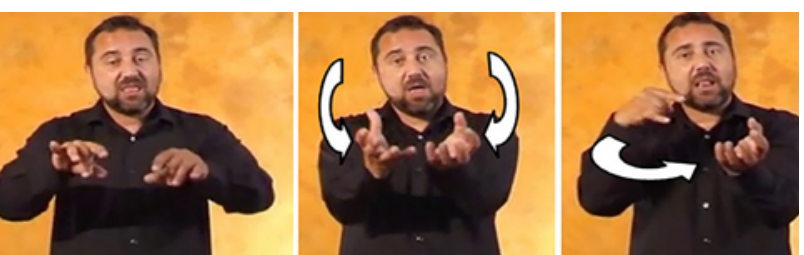

Figura 37. Ejemplo de búsqueda, SATÉLITE.ARTIFICIAL. Fuente: STS

Los neologismos que proponemos para SATÉLITE.ARTIFICIAL y SATÉLITE.NATURAL, siguen la misma forma: en ambos la mano pasiva adquiere una configuración que hace referencia a la forma del planeta alrededor del cual gira el satélite. Como se puede ver en las imágenes que mostramos a continuación de este párrafo, en el caso del satélite artificial la mano dominante adquiere forma de CERO, completamente cerrada en forma de esfera -pudiendo tomar, también la configuración dactilológica $\mathrm{C}$ - mientras que en el caso del satélite natural, la configuración es de C, en este caso la mano no se cierra completamente para diferenciar el tamaño del planeta y el del satélite. Por su parte, la mano dominante toma la configuración CERO en el caso del satélite natural y la de AVIÓN en el caso del artificial como consecuencia sus formas diferentes.
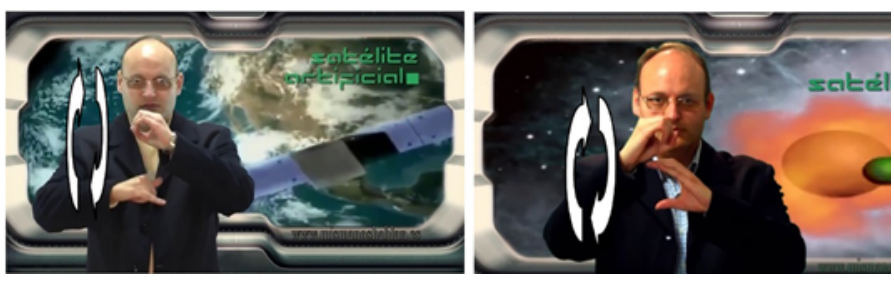

Figura 38. Neologismos SATÉLITE.ARTIFICIAL y SATÉLITE.

NATURAL. Fuente: MMH (2016b y 2014b)

\section{- Cohete}

Esta entrada tanto en Pinedo (2000) como en Sématos hace referencia a los explosivos o fuegos de artificio que constan "de un canuto resistente cargado de pólvora y adherido a los extremos de una varilla ligera" (RAE, 2018). Por su parte, STS nos proporciona el Signo buscado. Resulta llamativo que una misma fuente -STS- emplee dos Signos distintos para COHETE: uno el que usa en astronauta -consultar la Figura 36- y el otro el que proporciona en la entrada para cohete.
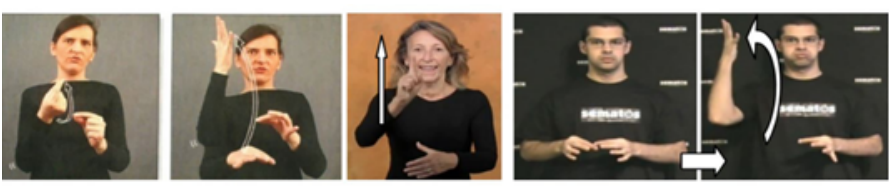

Figura 39. Ejemplo de búsqueda, COHETE. Fuente: Adaptado de Pinedo (2000, p. 283), STS y Sématos.

El Signo que recogemos en el material audiovisual difundido $-y$, que empleamos siempre que es necesario: por ejemplo, en astronauta- es el aportado por STS.

\section{- Viaje espacial}

En STS encontramos la entrada: VIAJAR+COHETE interpretado como viaje en cohete, que no se corresponde con nuestra búsqueda, al ser los viajes en cohete un tipo concreto de viaje espacial. 


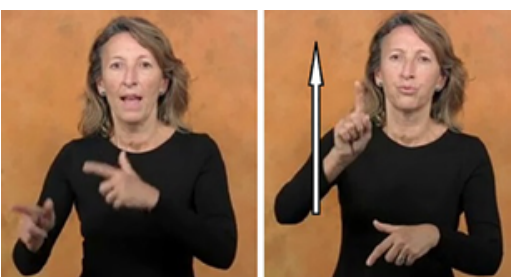

Figura 40. Ejemplo de búsqueda, VIAJE.EN.COHETE. Fuente: STS

Se entiende por viaje espacial: a todos los desplazamientos fuera de la atmósfera terrestre. Por tanto, la combinación secuencial de tres unidades léxicas: VIAJAR+ ATMÓSFERA+ FUERA. DE.ATMÓSFERA, es nuestra propuesta de neologismo.

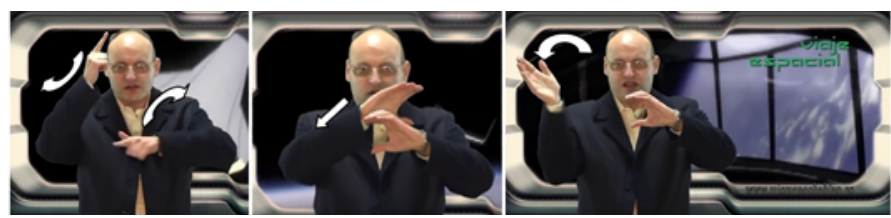

Figura 41. Neologismo, VIAJE.ESPACIAL. Fuente: MMH (2016b)

\section{Conclusiones}

Las temáticas tratadas en esta parte del estudio nos han permitido confirmar la existencia de errores o carencias léxicas en los materiales de la LSE vinculados a ámbitos especializados del saber que demandan la mejora y actualización de estas fuentes (objetivo 1) y establecer un método de trabajo, sistematizado y caracterizado por su adecuación a cualquier ámbito o rama del conocimiento (objetivo 2) que cristaliza en: la propuesta y difusión de neologismos (objetivo 3) vinculados a ámbitos o ramas especializadas del saber y el diseño de materiales audiovisuales en los que se fomenta el desarrollo y asimilación, mediante el uso combinado de texto e imágenes, de una imagen acústica o idea-fundamento asociada a cada concepto (objetivo 4). Por ende, nuestras aportaciones contribuyen a que la LSE se adecue a las necesidades lingüísticas de los individuos signantes, favoreciendo la labor del ILSE en las aulas y al mismo tiempo, el acceso al curriculum por parte de los alumnos Sordos y, en definitiva, el proceso de enseñanza-aprendizaje del alumnado usuario de la LSE.

Además, tal y como hemos reflejado en el presente estudio, independientemente de la escasez y calidad de los materiales lexicográficos de la LSE se ha demostrado que el estudio y empleo de los recursos propios de la LSE de forma correcta suplen las carencias y/o incongruencias detectadas en los diccionarios y glosarios. En este sentido, tras el trabajo desarrollado, estamos en condiciones de afirmar que el conocimiento profundo de la LSE y de la jerga del ámbito a interpretar/traducir permite afrontar un proceso de creación de neologismos que favorece que la LSE continúe enriqueciéndose. En definitiva, las carencias lexicográficas no son insalvables pero su existencia puede dar lugar a malas interpretaciones independientemente de la profesionalidad y buena disposición del intérprete de LSE. La escasez de léxico durante una "interpretación simultánea, de por sí sumamente difícil, obliga casi automáticamente a utilizar el español señado" (Sánchez, 2014; p. 11) y en el mejor de los casos -que no se recurra al bimodal o español signado- la influencia de la lengua oral en forma de calcos, vocalizaciones y empleo del dactilológico dará lugar a interpretaciones de baja calidad o cuyo contenido no será accesible para las personas exclusivamente signantes. En consecuencia, hemos evitado fomentar en los Signos creados la influencia de la lengua oral sobre la LSE adecuándonos a las necesidades de las personas Sordas signantes; al tiempo que se facilita el trabajo previo del in- térprete y los procesos de interpretación y de enseñanza-aprendizaje en las aulas y, en consecuencia: la inclusión.

Como conclusión general, podemos decir que, a pesar de las carencias detectadas en los materiales de la LSE, la Lengua de Signos Española (LSE) es una lengua rica y viva cuyo potencial está desaprovechado. Tal y como hemos demostrado, cualquier vocablo de una lengua oral puede transmitirse mediante una lengua de modalidad viso-gestual. Todas estas cuestiones las abordamos actualmente de manera integrar cuando planteamos y desarrollamos ecosistemas de formación (Álvarez-Arregui y Arreguit, 2019).

\section{Referencias bibliográficas}

Álvarez-Arregui, E. y Arreguit, X. (2019). El futuro de la Universidad y la Universidad del futuro. Aula Abierta, 48, 4, 447- 479 doi: https:/ /doi.org/1017811/rifie.48.4.2019.349-372

Aroca Fernández, E.; Díez Abella, Ma A.; Isa de los Santos, D.; Lima Montero de España, $M^{a}$ del C.; Nieto Caldera, $M^{\mathrm{a}} \mathrm{J} . \mathrm{y}$ Sánchez Carmona, E.M. (2002). Glosario de Lengua de Signos Española. 10. Educación: Geografía. Madrid: Fundación CNSE.

Chapa, C. (2000). La Dactilología. En A. Minguet Soto (coord.), Signolingüística. Introducción a la lingüística de la L.S.E. (pp. 201-206). Valencia: Fundación Fesord C.V.

De Candé, R. (2002). Invitación a la música. Pequeño manual de iniciación. México: Fondo de Cultura Económica.

De la Vega Sestelo, P. y García-Palao R., A. (2008). Teoría del lenguaje musical y fichas de ejercicios. Cuarto curso de grado elemental. Málaga: Ediciones Si Bemol S.L.

De Saussure, F. (1945). Curso de lingüística general. Buenos Aires: Editorial Losada. Recuperado de https:/ /goo.gl/GVq0Ru

Fernández Soneira, A. M. (2008). La cantidad a manos llenas. La expresión de la cuantificación en la lengua de signos española. Madrid: Fundación CNSE.

Fernández Villabrille, F. (1851). Diccionario usual de mímica y dactilología. Madrid: Imprenta del Colegio de Sordo-Mudos y Ciegos.

Ferreiro Lago, E y Aroca Fernández, E. (2008). Cambio cultural, normalización lingüística de la lengua de signos española. Madrid: Fundación CNSE.

Fundación CNSE (2008). Diccionario normativo de la lengua de signos española. Versión 1.0. Madrid: Fundación CNSE.

Fundación CNSE (2011). Diccionario normativo de la lengua de signos española. Madrid: Fundación CNSE.

Fundación CNSE (2013). Diccionario visual: Lengua de Signos Española-inglés-español. Madrid: Fundación CNSE.

Herrera Fernández, V. (2005). Adquisición temprana del lenguaje de signos y dactilología. Revista Psicopedagogica Repsi, 77-78, 2-10.

Herrero, A. (2000). La semiótica. Signos y dimensiones semióticas. En A. Minguet Soto (coord.), Signolingüística. Introducción a la lingüística de la L.S.E. (pp. 17-24). Valencia: Fundación Fesord C.V.

Ley $27 / 2007$, de 23 de octubre, por la que se reconocen las lenguas de signos españolas y se regulan los medios de apoyo a la comunicación oral de las personas sordas, con discapacidad auditiva y sordociegas. Boletín Oficial del Estado. Madrid, 24 de octubre de 2007, núm. 255, pp. 43251- 43259.

Marroquín Cabiedas, J. L. (1975). El lenguaje mímico. Caja de Ahorros de Jerez.

MMH - Mis Manos Hablan. (2014a, marzo, 12). Técnicas artísticas pintura al óleo - Lengua de Signos Española - LSE. [Archivo de vídeo]. Disponible en https://youtu.be/Oq7-MRevZMI 
MMH - Mis Manos Hablan. (2014b, mayo, 16). Cuerpos celestes - Lengua de Signos Española - LSE. [Archivo de vídeo]. Disponible en https://youtu.be/KimO4s9VoMs

MMH - Mis Manos Hablan. (2014c, junio, 1). Notas Musicales Método Kodaly - Lengua de Signos Española - Lengua señas. [Archivo de vídeo]. Disponible en https://youtu.be/qBTdv3x7i7M

MMH - Mis Manos Hablan. (2014d, septiembre, 25). Música, Parte 1 - Lengua de Signos Española - LSE. [Archivo de vídeo]. Disponible en https:/ / youtu.be/6HqTepRcGTM

MMH - Mis Manos Hablan. (2015, mayo, 18). Océanos - Lengua de Signos Española - LSE. [Archivo de vídeo]. Disponible en https://youtu.be/ttbWCWM1jeY

MMH - Mis Manos Hablan. (2016a, febrero, 24). Audiovisuales - Lengua de Signos Española - LSE. [Archivo de vídeo]. Disponible en https:/ / youtu.be/McZbu3BbU7g

MMH - Mis Manos Hablan. (2016b, marzo, 17). Vehículos espaciales y otros términos relacionados con el espacio. [Archivo de vídeo]. Disponible en https:/ / youtu.be/MIc7MkBUBJY

MMH - Mis Manos Hablan. (2016c, mayo, 31). Términos inmobiliarios, inmuebles - Lengua de Signos Española - LSE. [Archivo de vídeo]. Disponible en https:/ / youtu.be/szHCvkHiipg

Pedrell, F. (2009). Diccionario técnico de la música. (Ed. Facsímil). Valladolid: Editorial MAXTOR.

Pinedo Peydró, F. J. (1981). Diccionario mímico español. Valladolid: Federación Nacional de Sordos de España.

Pinedo Peydró, F. J. (1989). Nuevo diccionario gestual español. Madrid: CNSE.

Pinedo Peydró, F. J. (2000). Diccionario de Lengua de Signos Española. Madrid: Fundación CNSE.

RAE - Real Academia Española. (2018). Diccionario de la lengua española (23a . ed.). Consultado en http://www.rae.es/rae. html

Rodríguez González, M. A. (1991). Lenguaje de Signos. Madrid: Confederación Nacional de Sordos de España, CNSE / Fundación ONCE.

Rodríguez-Martín, A. y Álvarez-Arregui, E. (2017). Presentación del monográfico Educación inclusiva: avances desde la reflexión, la práctica y la investigación. Aula Abierta, 46, 5-8. doi: https://doi.org/10.17811/rifie.46.2.2017
Sánchez, C. (2014). De cómo, ganando una batalla tras otra, se está perdiendo la guerra. [Facilitado por el autor el 16-02-2014]

SDM - Sociedad Didáctico-Musical. (1979). Teoría de la música. Parte primera. Madrid: Villena, Artes Gráficas.

Sématos. (2009-2013). Diccionario de Lengua de Signos en línea. Disponible en: http:/ / www.sematos.eu/lse.html/.

Serrat Manén, J. y Fernández-Viader, M. P. (2015). Una aproximación a los referentes informativos de las personas sordas. Revista española de discapacidad, 1(1), 179-194. Recuperado de https: / /goo.gl/a7RDnH

STS - Spread The Sign. A multilingual dictionary for sign languages: "spreadthesign". Disponible en: http://www.spreadthesign. $\mathrm{com} / \mathrm{es} /$.

Tavares Correia, A; Ferreira Lima, R. A. y Lima, F. J. (2010). Datilología, tradução ou "oralização sinalizada"?. Ponencia Presentada en el Congreso Nacional de pesquisas em tradução y interpretação ce Libras E Língua Portuguesa. Lisboa, Portugal. Recuperado de http://goo.gl/8pLLfW

Valdés González, A. (2017). Personas sordas y aprendizaje de las materias científico-técnicas en la ESO. Dificultades derivadas de las carencias en la Lengua de Signos Española (LSE) y propuestas de mejora. (Tesis Doctoral). Universidad de Oviedo, Asturias.

Valdés González, A.; Álvarez Arregui, E. y Rodríguez Martín, A. (Junio, 2017a). Mis Manos Hablan. Póster presentado a las VI Jornadas Internacionales de Doctorado. Mieres, Asturias.

Valdés González, A.; Álvarez Arregui, E. y Rodríguez Martín, A. (2017b). Proyecto "Mis Manos Hablan". Materiales lexicográficos de la Lengua de Signos Española (LSE). En Universidad de Oviedo, Universidad, Investigación y conocimiento: avances y retos (pp. 207-212). Asturias: Servicio de Publicaciones Universidad de Oviedo.

Vázquez, A. (2010). Aproximación a la concepción de Signo y de Símbolo en Charles Sanders Pierce. Revista de Epistemología y Ciencias Humana, 2, 11-22.

VV.AA. (2002-2003). Glosarios temáticos de la Lengua de Signos Española: Nuevas Tecnologías, Religión, Economía, Matemáticas, Lengua y Literatura, Ciencias Naturales, Historia y Arte, Filosofía, Física y Química, Geografía, Sociedad y Política, Derecho, Sexualidad, Psicología y Medicina. Madrid: Fundación CNSE. 